Motrivivência $\quad$ v. 28, n. 48, p. 241-264, setembro/2016

\title{
IDENTIDADE PEDAGÓGICA E CURRICULAR DA EDUCAÇÃO FÍSICA ESCOLAR: territórios de reconhecimento e legitimidade no Instituto Federal Catarinense
}

\author{
Paulo Fernando Mesquita Junior \\ Juares da Silva Thiesen²
}

\begin{abstract}
RESUMO
O presente trabalho trata-se de um estudo realizado, no âmbito do Instituto Federal Catarinense (IFC), sobre o movimento de constituição da identidade pedagógica e curricular da Educação Física (EF) e sua legitimidade. O problema de pesquisa ficou sintetizado na seguinte questão: como vem sendo constituída a identidade pedagógica e curricular da EF no âmbito do IFC? Caracteriza-se como um trabalho de caráter qualitativo, de base exploratória e estudo de caso. Os principais procedimentos para a obtenção das informações foram: análise documental, observação participante e entrevistas semiestruturadas. Dentre os achados da pesquisa, em síntese, concluiu-se que: i) as experiências dos sujeitos com a disciplina de Educação Física, enquanto alunos do ensino básico, assim como a constituição profissional do professor de EF caracterizaram-se com predominância de situações de ensino-aprendizagem voltada ao conteúdo esporte; ii) a prática pedagógica dos professores de EF está sustentada basicamente em duas perspectivas curriculares: tradicional e crítica; iii) o reconhecimento social da EF como disciplina curricular ainda não está consolidado pela comunidade escolar.
\end{abstract}

Palavras-chave: Educação Física Escolar; Prática Pedagógica; Currículo; Identidade

1 Mestre em Educação. Professor do Instituto Federal Catarinense (IFC). Santa Rosa do Sul/Santa Catarina, Brasil. E-mail: paulo.junior@ifc-sombrio.edu.br

2 Doutor em Engenharia e Gestão do Conhecimento. Professor Ajunto do Departamento de Educação da Universidade Federal de Santa Catarina (UFSC). Florianópolis/Santa Catarina, Brasil. E-mail: juaresthiesen@gmail.com 


\section{INTRODUÇÃO}

Neste trabalho propusemos compreender o movimento de constituição da identidade pedagógica e curricular da Educação Física e sua legitimidade no âmbito do Instituto Federal Catarinense. Assumindo como ponto de vista metodológico, o trabalho como de caráter qualitativo, de base exploratória e estudo de caso. Utilizamos como principais procedimentos para a obtenção das informações: análise documental, observação participante e entrevistas semiestruturadas.

No sentido do objeto deste estudo, entendemos que a compreensão sobre currículo no contexto educacional, em perspectiva histórica, tem possibilitado aos pesquisadores e educadores atuar em esferas do debate e da ação pedagógica, desde o âmbito das proposições curriculares nacionais até o espaço curricular da disciplina e das experiências vivenciadas pelos estudantes na escola. Como bem destacam Nunes e Rúbio (2008), compreende-se que a análise a respeito dos currículos da Educação Física Escolar (EFE) deva ser promovida à luz do movimento histórico em que eles são construídos.

A Educação Física Escolar brasileira, na sua constituição histórica, vem sendo marcada por diferentes paradigmas, alguns deles com caráter fortemente acentuado como, por exemplo, as tendências eugenista/higienista, militarista e esportivista. São paradigmas que, de alguma forma, ainda hoje implicam a prática pedagógica da área, algumas ligadas à representação de diversos papéis determinados por interesses de classe. Neste sentido, Marques (2000, p. 19) apresenta que "a política da educação no Brasil foi sempre marcada por padrões verticalistas e centralistas a partir do núcleo do Estado", o que não se mostra diferente na EFE, que historicamente tem assumido papéis consoantes com práticas quase sempre vinculadas a ordenamentos da prescrição curricular, as quais respondem a interesses de grupos políticos e econômicos.

Cabe destacar que, a partir da década de 1980, inicia-se nova mudança de enfoque em relação à prática da Educação Física no contexto escolar. Emerge forte discussão pautada numa concepção crítica de educação, o que, por consequência, modifica (ou busca modificar) o caráter do seu papel político e pedagógico. Alguns autores (BRACHT, 1997/1999/2003; MOREIRA, 1999; CAPARROZ, 2003; PALMA et al., 2010) identificam esse momento como o período de "crise de identidade" da EFE.

Em síntese, quando se toma o percurso histórico da constituição da EFE e se observa o movimento das tendências, torna-se possível afirmar que os anos 1980 figuram como um divisor de águas entre o paradigma tradicional, que incorpora as tendências higienista/eugenista e esportiva, e o paradigma crítico, que contempla abordagens como a crítico-superadora e a crítico-emacipatória, além, é claro, de aspectos das abordagens pós-críticas, como é o caso do multiculturalismo crítico.

Outro aspecto relevante a considerar, especialmente no decurso da vigência do paradigma crítico, refere-se às limitações entre a produção teórica construída no âmbito acadêmico e a efetivação de propostas com esta perspectiva nos currículos escolares. Como revela Fonte (2001), a produção acadêmica em torno de uma EFE numa perspectiva de um currículo crítico avançou a ponto de assumir uma posição de hegemonia dentro dos muros acadêmicos, 
porém, foi e vem sendo incorporada muito timidamente pelas práticas pedagógicas dos professores de EFE na escola.

Hipoteticamente se pode afirmar que este movimento chega ao final do século XX e início do XXI com certo nível de maturidade no que se refere à reflexão crítica, acompanhado pelo adensamento das produções acadêmicas, porém, com frágil repercussão no interior da escola. Neste sentido, o esforço empreendido pelos pesquisadores não consegue romper, na prática, com a hegemonia dos modelos tradicionais. A EFE permanece com status de uma disciplina de "segunda classe", como se fosse um apêndice, uma disciplina auxiliar no contexto escolar (BRACHT e RODRIGUES, 2010; SELBACH, 2010; BRACHT et al., 2012).

Sendo assim, constantemente nos púnhamos a questionar sobre o porquê de a EFE ser considerada uma disciplina de menor prestígio em relação a outras. Por que ela é vista como prática que se caracteriza somente pelo cuidado com o corpo? Por que, muitas vezes, é utilizada para organizar a grade de horários, favorecendo outras disciplinas? Por que suas necessidades e finalidades são relegadas a um "segundo plano"? Por que é concebida muito mais como espaço de lazer, recreação e descontração, do que como espaço de ensino/aprendizagem? Por que, na escola, permanece uma visão equivocada da sua função pedagógica e curricular, especialmente quando comparada com o que vem sendo construído pelo campo científico da área? Por que, na escola, há dificuldades em se perceber o quanto ela pode contribuir para o processo formativo dos estudantes? Seriam a legalidade e os interesses políticos os únicos fatores que garantiriam que a
Educação Física (EF) continuasse sendo exigida e ofertada na escola? A EFE não conseguiria legitimar o seu espaço na escola por sua relevância pedagógica e curricular?

Enfim, acreditamos que as maneiras de se olhar o mundo, de se viver em sociedade, de constituir-se homem/mulher, de trabalhar, de realizar escolhas e de desenvolver ações humanas são, em geral, construídas histórica e socialmente. Do mesmo modo, entendemos que a EFE é constituída a partir de um contexto de relações sociais e de determinados processos históricos. É, assim como muitos outros, um campo que não se constitui e se desenvolve de forma neutra e independente.

Os conceitos de identidade e legitimidade adotados nesta pesquisa apoiam-se, principalmente, nos estudos de Bracht (1989, 1995, 1997), Lovisolo (1996), Cunha (2008), e Nascimento e Farias (2012). Bracht (1995) afirma que a identidade da EF se constitui por aquelas características que a diferenciam enquanto uma prática social específica, definindo seu estatuto próprio e ao mesmo tempo diferenciando-a de outras práticas sociais. Para ele, é na e pela instituição escola que a EF vem constituindo sua identidade e, sem dúvida, "a questão dos objetivos e conteúdos (métodos de ensino) da Educação Física é um dos pontos centrais do desenvolvimento da sua identidade pedagógica" (1997, p.24).

Identidade que não é fixa nem estável, que se modifica de acordo com o tempo e contexto, e que está associada com as relações estabelecidas com a EF durante o período que compreende a formação inicial, com as experiências da história da vida dos sujeitos, anteriores à formação, e também com a intervenção profissional (NASCIMENTO e FARIAS, 2012). 
No que se refere à concepção de legitimidade, é interessante observar que há certa confusão com relação ao conceito de legalidade. Para Bracht (1989), "a última tende a subsumir a primeira" (p.14). No entendimento de Lovisolo (1996), Bracht (1997) e Cunha (2008), a legitimidade implica o conjunto das questões derivadas e vinculadas com a regulamentação legal da vida profissional e com o reconhecimento social e cultural das profissões. Portanto, compreende-se que na EF a legitimidade deve ser constituída por sua legalidade como elemento curricular obrigatório da base nacional comum da educação básica nacional, combinada com o reconhecimento, por parte de toda a comunidade (escolar e extraescolar), da importância da sua inclusão e permanência no currículo escolar.

Reconhecimento que, segundo Bracht (1997), deve dar-se muito mais pela força de argumentos plausíveis, por princípios e códigos próprios, do que pelo argumento da força (legalidade). Ideia de legitimidade que se entende similar ao conceito de território de Cunha ${ }^{3}$ (2008). No sentido do que pensa Maria Izabel Cunha sobre território, poder-se-ia afirmar que a legitimidade se dá pela força dos sentidos e significados da disciplina no contexto escolar à medida que, se tornando uma cultura preponderante, torna-se capaz de confrontar forças neste lugar chamado escola, assumindo-se como um território.

Por conseguinte, o movimento de constituição da identidade pedagógica e curricular da EFE, no que se refere a sua legitimidade, pode, aqui, ser entendido como um processo social que se constrói com base nos significados sociais e nas suas tradições, que evolui continuamente e historicamente e que pode ser influenciado pelo próprio contexto escolar, pelas crenças, pelos valores, pela formação inicial, pelas experiências passadas, assim como pela prática pedagógica exercida no ofício da docência. Movimento que, combinado com as relações sociais que o sujeito (professor de EF) estabelece com os demais sujeitos envolvidos no contexto escolar, e de acordo com o processo histórico, a diferencia das demais disciplinas escolares, conferindo-lhe um sentido próprio, para si e para os demais sujeitos, e que pode (deve) implicar sobre o caráter de sua consolidação e legitimidade como componente curricular legitimamente necessário na educação formal.

No sentido do exposto até o presente, formalizamos o seguinte problema de pesquisa que se apresentou da seguinte forma: como vem sendo constituída a identidade pedagógica e curricular da EF no âmbito do Instituto Federal Catarinense (IFC)?

\section{Aprendendo com o campo: constituição da Identidade Pedagógica e Curricular da Educação Física e sua legitimidade no âmbito do IFC}

No presente trabalho, assumimos como concepção de pesquisa o conceito proposto por Minayo (2011, p. 16), para quem:

3 Cf. CUNHA, Maria Isabel da. Os conceitos de espaço, lugar e território nos processos analíticos da formação dos docentes universitários. Rev. Educação Unisinos, São Leopoldo, v.12, n 3, 182-186, setembro/dezembro 2008 . 
[...] pesquisa é a atividade básica da ciência na sua indagação e construção da realidade. É a pesquisa que alimenta a atividade de ensino e a atualiza frente à realidade do mundo. Portanto, embora seja uma prática teórica, a pesquisa vincula pensamento e ação. Ou seja, nada pode ser intelectualmente um problema se não tiver sido, em primeiro lugar, um problema da vida prática. As questões da investigação estão, portanto, relacionadas a interesses e circunstâncias socialmente condicionadas. São frutos de determinada inserção na vida real, nela encontrando suas razões e seus objetivos.

Com esse pressuposto, classifica-se a investigação como um estudo de cunho qualitativo inserido diretamente no ambiente educacional e escolar, neste caso, no Instituto Federal Catarinense campus Sombrio. Stenhouse (1975 apud SAN$\mathrm{CHO}, 2010)$ destaca que a escola é um dos espaços privilegiados para a pesquisa em educação, constituindo-se como um "laboratório" natural.

Ainda em relação à tipologia, esta pesquisa se caracterizou como um estudo de caso, uma vez que se ocupou em compreender o processo pedagógico e curricular em uma "única" instituição em uma dimensão mais específica (MOLINA, 2010), qual seja, a de compreender o processo de constituição da identidade pedagógica e curricular da Educação Física e sua legitimidade no âmbito do Instituto Federal Catarinense, especificamente no IFC campus Sombrio.

A imersão no campo teve duração de 15 meses e teve como locus mais específico a antiga Escola Agrotécnica Federal de Sombrio (EAFS/SC), hoje Instituto Federal Catarinense campus Sombrio, que está localizada no município de Santa Rosa do Sul, a $15 \mathrm{~km}$ da rodovia BR 101, um dos 15 municípios que fazem parte da Associação dos Municípios do Extremo Sul Catarinense (AMESC). Envolveu nove (09) professores, mais especificamente, quatro docentes de EF e cinco das demais áreas ${ }^{4}$, os nomes dos participantes foram alterados para garantir o sigilo da fonte.

A fim de coletar as informações necessárias para a realização deste estudo, utilizamos os seguintes instrumentos: análise documental, entrevistas e observação.

$\mathrm{Na}$ investigação utilizamos, dentre os diferentes tipos de entrevistas, a do tipo semiestruturada, de forma individual com cada docente, a partir de temas e assuntos relacionados à prática pedagógica e curricular. No total, foram realizadas nove (09) entrevistas, durante o período de outubro de 2013 a janeiro de 2014. Todas as entrevistas foram gravadas e autorizadas pelos entrevistados por meio do documento de esclarecimento e consentimento devidamente aprovado pelo parecer consubstanciado expedido pelo comitê de ética e pesquisa da Universidade Federal de Santa Catarina (UFSC). Posteriormente à realização da entrevista, realizamos a transcrição, seguida da devolução da entrevista aos entrevistados para que eles realizassem a leitura e análise do texto escrito.

As observações foram realizadas a partir de outubro de 2012 se estendendo até abril de 2014, utilizamos a observação

4 Linguagens e Códigos (Português), Ciências da Natureza Matemática (Biologia, Física) Ciências Humanas (História), Educação Profissional (Redação Técnica). 
participante e semiestruturada nas aulas de EF e demais situações, buscando observar os professores de EF em suas aulas e nos outros espaços escolares como reuniões, conselhos de classe, sala dos professores, como também os alunos na referida disciplina e em outros espaços. No total, foram realizadas 128 horas de observação. Registramos todas as informações obtidas (comportamentos, ações, atitudes, diálogos, falas, descrição dos sujeitos e locais) em fichas de observação. Ainda com relação a esse tipo de instrumento, utilizamos pautas prévias.

Como já destacado, a análise documental constituiu mais um dos instrumentos para a obtenção de dados e informações empíricas. Considerando-se o objetivo da investigação, atribuímos especial atenção a esse instrumento, especialmente em relação à preparação das entrevistas e a sua posterior análise. Assim, no âmbito dessa investigação, analisamos documentos oficiais e técnicos. Na ordem dos documentos oficiais incluímos os documentos orientadores da educação básica, como: Lei de Diretrizes e Bases da Educação Nacional (LDB) e Parâmetros Curriculares Nacionais da Educação Física (PCNs) e Orientações Curriculares para o ensino médio. Já os documentos técnicos revisados foram o Projeto Político Institucional (PPI), o Projeto Político do Curso (PPC) e os Planos de Ensino (PE) da disciplina de Educação Física.

Para a organização e análise das informações obtidas através do trabalho de campo utilizamos o método de análise de conteúdo. Mais especificamente, fez-se a análise qualitativa de conteúdo, que se utiliza de categorias normalmente obtidas a partir de modelos teóricos, tendo em vista que "as categorias são levadas para o material empírico e não necessariamente desenvolvidas a partir deste, embora sejam reiteradamente avaliadas em contraposição a esse material e, se necessário, modificadas." (FLICK, 2009, p.291). Para o trabalho de análise de conteúdo, seguimos as orientações de Lüdke e André (1986), organizando todo material e identificando nele conceitos, tendências e padrões relevantes para, em um segundo momento, reavaliar os achados, buscando relações e interferências por meio de uma leitura, em um nível de aprofundamento mais elevado, de todo o material produzido.

Por intermédio deste procedimento foi possível identificar as principais categorias presentes nos textos, as quais passaram a ser orientadoras do processo de análise no trabalho empírico. Assim, as categorias de análise, extraídas dos textos oficiais e, inclusive, dos referenciais teóricos produzidos no campo da EF, passaram a orientar a interpretação dos dados empíricos. Resultante desta organização, definimos quatro categorias de análise a partir das quais realizamos o trabalho de interpretação das informações obtidas por meio dos instrumentos de pesquisa já referidos, que apresentamos a seguir.

\section{As experiências vivenciadas com a disci- plina de Educação Física na trajetória de formação durante a Educação Básica pelos docentes entrevistados}

Nesta categoria, apresentamos aspectos que expressam as experiências que tiveram os docentes entrevistados do IFC durante suas trajetórias de formação na educação básica. Consideramos aspectos dessas experiências por entendermos que os sujeitos se constituem pelas relações que 
estabelecem com o outro e com o mundo nas diferentes situações da vida. Como permanecem inseridos na instituição escola por períodos de tempo significativos, acabam introjetando, desde as primeiras experiências de formação, conceitos, maneiras de pensar e de se posicionar sobre ensino e papel do professor (PAIXÃO SANTOS, 2002, p.97) e, neste caso, é possível que incorporem determinadas representações da EFE com implicações sobre suas práticas. Para Tardiff (2000) a cultura pessoal, que provém da história de vida e da cultura escolar anterior interfere na constituição da identidade docente dos professores.

A apreciação dos conteúdos das entrevistas com os professores revela que, de certa maneira, há similaridades entre as experiências vividas neste espaço/tempo e a representação de suas práticas. Os professores participantes deste estudo, em grande parte, tiveram suas experiências com a EF durante a educação básica em escolas públicas. Experiências que se caracterizam como momentos, em geral, prazerosos e de grande envolvimento com o esporte conteúdo predominante durante a formação na educação básica. Evidências disso se percebem nos relatos a seguir:

"As lembranças que tenho são coisas boas, mais muito ligadas as questões da atividade física, não muito a educação ${ }^{5}$, nessa época não era muito focado esse aspecto. Tínhamos voleibol, futebol de salão e futebol de campo" (Carlos).

"A gente gostava muito, só que a Educação Física naquela época era... Você sabe... jogavam uma bola. Às vezes era voleibol, outras futebol..." (Davi).
“Eu adorava Educação Física. Era a disciplina que eu mais gostava. Lembro que gostava muito de handebol, mas também de basquete, vôlei e futebol" (Abreu).

Parte das entrevistas apresentam indicativos de que a EF vivenciada baseava-se fundamentalmente no esporte. Percebemos, pelas entrevistas, ausência de práticas pedagógicas que fossem além do fazer pelo fazer, de ações motoras regulamentadas e padronizadas. Portanto, não há indicativos de comprometimento com processos ou formas de produção cultural em relação ao conhecimento da cultura corporal. A falta de uma visão mais ampla em torno da cultura corporal faz com que se percam oportunidades de promoção de aprendizagens significativas (PALMAS et al., 2010).

Embora a EF se caracterize como um campo que trata da cultura corporal permeada por um vasto repertório de saberes, o que observamos nas falas dos entrevistados é que havia certo monopólio de alguns conteúdos em detrimento de outros, e que estes foram ministrados sem sistematização mais consistente, sendo repetidos ano a ano durante todo o ensino básico, como constatamos na fala do professor Antonio "trabalhamos as quatro modalidades básicas de quadra: voleibol, handebol, futebol de salão e basquetebol. Basicamente regras, fundamento e jogo".

No contexto das entrevistas não ficou caracterizada, por exemplo, a preocupação mais acentuada com uma prática de ações motoras regulamentadas e padronizadas, tomando o caráter técnico e os

5 Carlos, quando fala de educação nesse momento, quis se referir aos aspectos conceituais, de uma prática pela prática. 
princípios do esporte de rendimento como elementos centrais, tão característicos, de acordo alguns autores (BRACHT, 1997; SOUZA JUNIOR, 1999; KUNZ, 2001b; SADI, 2001; NEIRA, 2007). O esporte, nas aulas de EF, acabou se configurando de outra forma, como sugere o relato de alguns dos entrevistados:

"Ele nos soltava para a quadra. Não me lembro dele dirigindo uma atividade na quadra. A gente escolhia" (Antonio).

“A Educação Física era muito aguarda$d a$, porque a gente sabia que ia jogar um futebol, correr. As aulas eram práticas, muito pouco teoria, regras e jogo" (Carlos).

"Jogava uma bola e deu, nós que nos virássemos" (Davi).

Evidenciamos, portanto, que o esporte foi o conteúdo quase que exclusivo nas aulas de EF vivenciadas pelos entrevistados, revelando certa supremacia das práticas voltadas ao esporte, tão características a partir dos anos 60. Darido (1999) e Dieckert (2007) comentam que tal supremacia ainda permanece dominante nos currículos escolares.

As falas também sugerem certo abandono, por parte dos professores, da prática pedagógica ligada ao compromisso com a formação dos estudantes. Indicam que os alunos, nessas aulas, se permitiam fazer o que bem entendessem, ficando a aula a cargo de suas vontades, o que faz supor certa desvalorização da disciplina, à medida que tudo ou quase tudo pode. Neste sentido Souza Junior (2001), em sua pesquisa, defende que esse cenário não seria algo específico somente do período vivenciado pelos entrevistados, mas também do atual, ou seja, a negação dos conteúdos e conhecimentos universais da cultura corporal aos alunos nas aulas de EFE a desconfigura como um componente curricular.

Outro aspecto também presente nas entrevistas e que chamou atenção, refere-se à questão das dispensas nas aulas de EF e da oferta no contraturno. A mesma legislação que garantia a legalidade, e que até hoje garante, visto que a EF é obrigatória nos currículos escolares, a tornava facultativa. Os próximos relatos evidenciam isto:

"Na minha época nós éramos dispensados da EF se trabalhávamos, ou por outros motivos, até chegávamos a utilizar atestados "frios", mentirosos. Eu me lembro da minha graduação e do meu filho no ensino médio, que eu tinha que pegar um atestado para livrarmos no da $E F^{\prime \prime}$ (Ana).

"A Educação Física era bem organizada. A Educação Física era à tarde, no contra turno, duas vezes por semana, e você escolhia a modalidade que queria realizar. Era uma coisa meio que você já sabia. Era para as equipes do colégio" (Maria).

A descrição feita por Ana desvela mais uma vez a preocupação da EF vivenciada pelos entrevistados apenas com a aptidão física e com o fazer corporal. Permanece a noção de uma prática do fazer pelo fazer, destituída de qualquer reflexão, perpetuando a visão dicotômica entre corpo e mente tão característica no movimento eugênico e higienista da EF, e que se mantém no movimento esportivista em propostas atuais.

Já a fala da professora Maria sinaliza que a oferta da $\mathrm{EF}$, em turno diferente daquele das demais disciplinas, caracterizava-a como 
uma disciplina dispensável, impossibilitando-a de se fazer presente efetivamente na proposta pedagógica da instituição escolar, o que gerava processos de isolamento. Percebemos, nesse cenário, certo descaso com relação ao direito dos jovens a uma educação plena e o desprestígio da disciplina.

Outro elemento que emerge na fala dos entrevistados diz respeito a certo sexismo presente nas aulas de EF. Sexismo que tem presença, de acordo com Castellani Filho (2006), desde os currículos prescritos na década de 1930 e que, segundo Bracht (1997), leva a EF a reforçar a esteriotipação do comportamento masculino e feminino. Para Kunz (2001b), este estereótipo é reforçado, normalmente, nas aulas concentradas no conteúdo esporte:

"No horário da EF os meninos se dirigiam para aula com um professor, e as meninas com uma professora" (Carla).

"Meninos e meninas eram juntos. Só que na hora de jogar era separado, podia machucar, os meninos eram mais fortes. Já na outra escola você escolhia a modalidade, então separava" (Maria).

"Não, não, eram turmas mistas sim. Mas claro, na hora do jogo separava-se meninos e meninas" (Carlos).

"Na hora de montar as equipes, dois alunos escolhiam, onde os ruins ficavam sempre por último. Meninos separados das meninas" (Antonio).

De modo geral, os fragmentos destacados das entrevistas revelaram aspectos significativos no que se refere às implicações decorrentes das experiências vivenciadas na trajetória de formação durante a educação básica na prática pedagógica dos professores de EF no IFC e na representação dos professores das demais áreas em torno da disciplina, o que, entendemos, concorre para a constituição da identidade e do reconhecimento da disciplina.

\section{A constituição profissional do professor de Educação Física: razões da opção pelo magistério e pela EF e aspectos sobre a formação inicial}

Ao realizar estudos sobre o tema, Januário (2012) define a constituição profissional do professor como um constructo decorrente das diferentes experiências vividas antes, durante e após a formação inicial ${ }^{6}$, quando a "formação deve ser considerada como um processo contínuo e multilateral" (p.24).

Manifestando-se a respeito dos processos de formação, Tardif (2000) ressalta que os saberes docentes são variados e heterogêneos e são provenientes de diferentes fontes. Em geral, são derivados da cultura pessoal, que provém de histórias de vida e de culturas escolares anteriores; dos conhecimentos adquiridos durante a formação na universidade; dos conhecimentos curriculares veiculados pelos programas, guias e currículos prescritos; e do saber da experiência de trabalho, na prática diária de professor. O processo de formação, por sua vez, tem interferência de instâncias exteriores (formação inicial), ou seja, onde os professores não são os produtores oficiais dos saberes; e de instâncias interiores

6 Entende-se, neste estudo, por formação inicial, a formação obtida pelo sujeito no curso de graduação. 
(experiência de trabalho, cultura de vida), onde os professores são os produtores desses saberes.

No conjunto dos elementos da análise empírica, buscamos identificar as razões que levaram os atuais professores da EF do IFC a optar pelo curso de EF, por quais motivos se aproximaram do magistério e quais as influências do processo de formação inicial que mais incidem sobre a docência. Os dados, quando analisados, abriram novas possibilidades de compreensão sobre o objeto de estudo desta pesquisa.

Renata comentou que a opção pela EF deveu-se ao gosto pelo esporte: "era uma disciplina que eu adorava, desde pequena eu me identificava muito, não tive dúvida, foi a minha primeira opção ${ }^{7 \prime}$. Abreu destacou que sempre esteve envolvido com esportes, e quando chegou a hora do vestibular optou pelo curso de EF, apesar da desconfiança por parte dos familiares: "Era o que eu queria, não havia o que fizesse eu mudar de opinião". São expressões que reafirmam a tese de Figueredo (2001), quando argumenta que os alunos que optam pelo curso de EF, em sua maioria, têm um fazer que, em algum sentido, antecede o seu ingresso no curso, que está identificado com determinados conteúdos da EF vivenciados como estudante, com esporte, dança, ginástica e outros que motivam a escolha do curso, pelos alunos, na formação profissional inicial.

Já os demais entrevistados disseram que almejavam ingressar em outras áreas profissionais antes de optarem pela EF. Para Antonio, que não tinha pretensão de ingressar no curso, a dúvida se desfez pouco antes de realizar o vestibular, primeiramente porque encontrou na licenciatura certa facilidade financeira, e também porque a vivência esportiva prevaleceu, conduzindo-o ao curso de EF.

Para Davi, no entanto, a decisão pela EF veio mais tarde, após cursar Odontologia por algum tempo. Mais uma vez, o vínculo com o esporte e o envolvimento com as pessoas, aparentemente proporcionado pela disciplina de EF, parecem ter sido os fatores preponderantes para a decisão:

"Eu sempre gostei de esportes. Até co-
mecei em outra faculdade, mas acabei
ficando na Educação Física... Eu a vejo
de forma diferente das outras discipli-
nas tenho um contato mais próximo.
Eles gostam do cara, não sei se é por
causa da disciplina" (Davi).

O conjunto das informações obtidas confirma certa diversidade de motivos para justificar a opção de professores pela docência na EF e coloca o esporte como motivação central para esta porta de entrada. Tais sinalizações remetem ao contexto histórico da EFE, mais especificamente, a partir da década de 60 , quando a instituição esportiva passa a ditar, na EFE, os rumos de sua identidade pedagógica e curricular, interferência esta que ainda se faz presente em muitas realidades escolares.

Em relação à formação inicial, os professores entrevistados disseram que ela ofereceu uma preparação mais voltada à prática desportiva do que à docência em instituição escolar. Entendemos esta constatação como uma crítica ao currículo mínimo de 69 que se caracterizava por um

7 Quando Renata fala em primeira opção, se refere à escolha do curso no vestibular. 
perfil tecnobiologizante do esporte, um currículo tradicional-esportivo, em que havia uma separação entre teoria e prática. Não obstante, é uma crítica também ao currículo de 87 , promulgado pela Resolução $n^{\circ}$ 03/87 do CFE, que intencionava uma formação mais consistente e que viesse a promover grandes avanços nesse processo formativo inicial, o que não se concretizou, como citado por alguns autores (DA COSTA, 1999; VAZ et al., 2002; SOUZA NETO, 2004; KRÜGER, 2007).

Outro aspecto interessante é que os professores interpretam a formação que tiveram na graduação como uma formação eminentemente tecnicista, com ênfase na transmissão de conhecimentos técnico-instrumentais, com ausência de pesquisa e com evidente distância da realidade escolar:

"A formação era voltada ao esporte. Era bastante técnica, por exemplo, a gente tinha natação I, II e III. Na natação I era só técnica, a Il era técnica e como dar aula de natação, e a III só trabalhava como dar aula de natação. Para trabalhar com esporte era uma formação boa, mas não éramos preparados para trabalhar na escola" (Renata).

Os saberes desenvolvidos nas disciplinas dos cursos de EF, segundo os participantes deste estudo, além de estarem fora do contexto, não correspondiam à necessidade real do universo escolar. Dessa forma, o conhecimento produzido na graduação não possibilitou a aproximação entre teoria e prática, em função da desarticulação entre os conteúdos da graduação e a prática docente escolar. Vejamos o que afirmou Davi: "a realidade da faculdade e da escola são diferentes. Você chega na escola pública não tem material, as turmas são numerosas, tem aluno que não gosta... A gente na faculdade aprende a treinar os esportes, mas em uma realidade diferente da escola".

Percepções similares manifestaram Renata e Antonio, que destacaram a distância entre o saber da graduação e o saber da experiência prática. Ambos começaram a trabalhar antes de concluir a graduação, o que lhes permitiu estabelecer comparações entre os dois saberes:

\begin{abstract}
"Tudo dava certo na faculdade, mas na escola a realidade era outra. Penso que a universidade não prepara para a sala de aula. A universidade traz uma grande carga de conhecimentos, mas pouco articulados com a realidade escolar" (Antonio).
\end{abstract}

Quando aborda este tema, Nóvoa (1995, p. 25) declara que "a formação deve estimular uma perspectiva crítico-reflexiva, que forneça aos professores os meios de um pensamento autônomo e que facilite as dinâmicas de auto formação participada". Segundo o autor, a formação não se constrói apenas por acumulação de conhecimentos, mas também pela reflexão crítica sobre as práticas, sendo importante conferir "um estatuto ao saber da experiência" (NÓVOA, 1995, p.25).

Para Vaz et al. (2002), a formação deve buscar uma aproximação com a realidade escolar brasileira, desde as primeiras fases do curso de EF, de forma planejada, sistemática e dialética, rompendo, assim, com a formação técnica linear, como se viu nas narrativas dos entrevistados quando se referem à suas experiências de formação. Em certa medida, ficou explícito que houve alguma deficiência na formação acadêmica, no que se refere a preparar futuros professo- 
res para atuarem no ambiente escolar. Os depoimentos apenas confirmam as históricas lacunas existentes entre o conhecimento da universidade e o conhecimento exigido na prática escolar.

Abordamos, a partir de agora, o último aspecto proposto sobre a constituição dos professores de EF investigados, ou seja, a aproximação com o magistério. As trajetórias de aproximação dos professores de EF entrevistados com o magistério apresentaram uma similaridade, com início antes mesmo do término da graduação pela maioria, mas também houve aqueles que ingressaram mais tardiamente. Para alguns, a experiência no ensino da EFE, iniciada ainda durante a graduação, confirma a possibilidade e importância da aproximação com a realidade escolar.

Observamos, nas falas dos professores, que a aproximação com a realidade escolar é importante, aspecto com o qual se concorda, mas é preciso destacar que a docência se dá, primeiramente, mediante situações entre pessoas, o que envolve um trabalho com o coletivo humano, exigindo uma formação de qualidade, devido à complexidade do ato da docência escolar. Assim, seria correta essa inserção na escola, antes mesmo do final da graduação? Não seria possível, talvez, pensar em uma alternativa para realizar essa aproximação com a realidade escolar a partir da graduação? Como se tem pensado esta questão na universidade? Estes são questionamentos que surgiram e que ficam como sugestão, quem sabe, para estudos futuros.

\section{Prática Pedagógica e Curricular}

Por intermédio desta categoria, buscamos compreender como os professores de EF entrevistados vêm constituindo o seu fazer pedagógico no IFC. Na análise, procuramos estabelecer uma relação das observações realizadas nas aulas ministradas pelos professores com os documentos oficiais que serviram como fontes de pesquisa. Partimos do pressuposto de que este movimento dos professores de EF caracteriza-se com um dos fatores que influenciam fortemente na identidade pedagógica e curricular da EFE, e que a busca da compreensão deste movimento em um espaço/tempo específico pode contribuir para o entendimento sobre aspectos gerais e específicos que envolvem a disciplina no contexto escolar.

No que se refere ao planejamento, este foi analisado sob duas perspectivas: o planejamento das aulas em EF, pensado e organizado pelos próprios professores, e o planejamento da disciplina, que envolve os professores e a equipe de coordenação pedagógica da instituição. Sobre o planejamento das aulas, consideramos a estrutura que estas assumem na execução do planejado, contemplados aí os espaços e materiais pedagógicos disponíveis, os objetivos, as metodologias e a avaliação. Neste âmbito, identificamos movimentos coerentes entre o prescrito e o realizado e movimentos visivelmente discrepantes.

Verificamos, por exemplo, que alguns professores (ABREU e DAVI) não planejam suas aulas por meio de registros escritos, o que indica a manutenção de uma estrutura de aula historicamente instituída, própria de modelos que incluem aquecimento, apresentação de fundamentos e execução do jogo propriamente dito. É, segundo SADI (2005), a estrutura predominante nas aulas pautadas na instituição 
esportiva. Nesse âmbito, o planejamento se torna secundário ou até mesmo dispensável. A inexistência ou a falta de registro escrito não significa que os professores não planejem suas aulas, contudo, indica baixo investimento no quesito inovação e criatividade pedagógica, o que, na visão de Molina Neto (1998), contribui para que a EFE se caracterize e seja identificada especificamente pelo fazer.

Para outros professores, a questão do planejamento escrito apresentou-se como algo importante e necessário (ANTONIO e RENATA), conforme ilustra o relato a seguir: "planejo cada aula e procuro colocar no papel. Sem o registro pode-se correr o risco do esquecimento, não há como voltar e rever, repensar o que deu certo, o que precisa mudar" (RENATA). É evidente que a ação de planejamento implica na qualidade do processo ensino-aprendizagem ao mesmo tempo em que rompe com uma velha tradição que situa a EF como atividade que dispensa cuidados e registros em relação às estratégias de ação.

No que se refere ao planejamento da disciplina, que envolve a participação de professores e da equipe coordenadora da instituição, observamos que havia certo descontentamento no que tange ao apoio pedagógico recebido. Os professores argumentaram que quase não recebiam orientações e que, quando recebiam, estas não correspondiam às suas necessidades, eram, por vezes, ligadas a questões burocráticas como, por exemplo, entregar o plano de ensino no formato exigido no prazo estabelecido. Quando questionados sobre a sua participação nas atividades de planejamento, os professores disseram que, em alguns casos, o plano era feito de forma coletiva entre os professores de EF, mesmo assim, tinha um sentido eminentemente burocrático. Ficou explícito, nas falas, que os entrevistados se ressentiam da oportunidade de planejar de forma coletiva e vinculada a proposta pedagógica da instituição, e que este seria o procedimento mais adequado. Inclusive, apontaram a criação de um espaço específico para a discussão do coletivo da EF como alternativa que ajudaria a disciplina.

Neste sentido, Ferraz e Correia (2012) ressaltam a importância da superação do individualismo entre os docentes, a favor da concretização de relações pautadas por uma dimensão coletiva. Compreendemos que um espaço específico de planejamento, para a área da EF na escola, é uma alternativa preciosíssima, pois possibilitaria um espaço/tempo de reflexão e planejamento sobre a prática pedagógica da disciplina. Outro aspecto que incidiu sobre a prática pedagógica, no âmbito do planejamento, foram as discussões coletivas, em cuja observação revelou-se frágil. Os espaços de reuniões pedagógicas, na ótica dos sujeitos entrevistados, tem se caracterizado como pouco produtivo em relação às questões pedagógicas: "as reuniões pedagógicas tem se configurado muito mais como administrativas do que pedagógicas" (ANTONIO).

Quando os professores falaram sobre conteúdos, estratégias e formas de avaliar, não se posicionaram de forma unânime. Para alguns (ABREU e DAVI), o esporte apareceu como principal conteúdo, mais especificamente, as modalidades de futsal, handebol, voleibol e basquetebol. Os depoimentos dos referidos professores também convergem no que se refere às estratégias utilizadas. Ambos disseram que 
costumam ministrar aulas práticas focadas no aspecto procedimental ${ }^{8}$, seguindo certa estrutura (aquecimento, fundamentos e jogo). O fato de haver dificuldades de articulação entre as dimensões conceitual e procedimental na ação pedagógica revelou o quanto à disciplina ainda está presa a uma concepção que se justifica no fazer pelo fazer, portanto, distante das orientações teóricas pautadas seja nas orientações curriculares mais atuais, seja nas perspectivas críticas que pesquisadores vêm produzindo no campo acadêmico. Essa limitação, sem dúvida, reduz a possibilidade de os estudantes acessarem outros níveis de conhecimento, de experiências e, por extensão, o próprio acervo cultural da humanidade.

Outros professores, distintamente, quando falam sobre os conteúdos e estratégias, destacam que se baseiam nos temas da cultura corporal, buscando uma articulação como o contexto da realidade discente, tendo o planejamento como referência para a opção por estes saberes. Observou-se ainda que, de forma diferente dos demais, estes professores buscam superar, por exemplo, a centralidade no esporte, consequentemente, optando pela ampliação do escopo de conteúdos/conhecimentos que compõem a EFE, o que revela avanços na direção de uma EFE mais identificada com os atuais pressupostos teóricos e metodológicos da área. Para Rosário e Darido (2005, p. 172), a "diversidade de conteúdos é considerada um ponto positivo na construção de uma sistematização ou de um planejamento, principalmente quando saem do eixo esportivo".
Em se tratando da forma como os professores de EF avaliavam os processos de ensino e aprendizagem, encontraram-se também semelhanças e diferenças em termos de concepção e procedimentos entre os dois grupos estabelecidos. Houve consenso, no grupo de entrevistados, de que avaliar é algo complexo, que suscita questionamentos e gera dificuldades, inclusive operacionais.

Em sentido amplo, a análise da categoria "prática pedagógica" permitiu a afirmação de que o trabalho dos professores abrange concepções e procedimentos distintos. Um grupo sustentava e organizava sua prática em referenciais considerados mais conservadores, ou seja, mantinha como predominantes os conteúdos vinculados às temáticas do "esporte", numa dinâmica que se limita ao chamado fazer pelo fazer, focada sobretudo no aspecto procedimental e, em certa medida, desvinculada do projeto pedagógico da instituição e das atuais orientações curriculares. Este movimento, que fragiliza a área no interior da instituição, também contribui para retardar ainda mais a consolidação da identidade da EF como um território.

De toda forma, havia na instituição outro movimento que buscava romper com esta lógica. Tratava-se de um grupo de professores que, preocupado com o fortalecimento da disciplina, assumia uma concepção de trabalho que dava centralidade aos conhecimentos relativos à cultura corporal e que eram metodologicamente tratados de forma crítica e reflexiva. Entendemos que

8 Segundo Darido (2010) os conteúdos na EF devem ser apresentados segundo as seguintes categorias, que são: conceitual ligado a fatos, conceitos e princípios, ou seja, trata do entendimento de como e porque realizamos movimentos corporais, as relações sócio históricas que neles interferem, etc. A categoria procedimental é ligada ao fazer. A categoria atitudinal é vinculada a normas, valores e atitudes. 
este é um dos caminhos para a superação da visão historicamente constituída da EFE, que legitimou a prática pela prática. Portanto, é possível concluir que, no âmbito da instituição, de certa forma, há um movimento de (re) configuração da sua identidade, visto que coexistem, na atualidade, práticas e discursos distintos. Como afirma Lovisolo (1995, p.24), "as identidades resultam dos discursos e das práticas dos homens".

\section{Reconhecimento Social}

No âmbito da compreensão sobre a legitimidade da EFE, assumida neste estudo, partimos do pressuposto de que a mesma se dá pela combinação de dois fatores preponderantes: sua oficialidade/obrigatoriedade como elemento curricular obrigatório e o reconhecimento social, pela comunidade escolar, da sua importância pedagógica e curricular. Visto que o primeiro aspecto, historicamente, sempre esteve garantido, cabe questionarmos o segundo, ou seja, o seu reconhecimento social. Nesse sentido, nesta categoria, buscamos apresentar como os professores de EF e das demais áreas, entrevistados, vêm reconhecendo a importância da disciplina no currículo e quais aspectos contribuem para a sua legitimação. Para a análise e interpretação das representações dos entrevistados, buscamos apoio teórico em Cunha (2008), a partir da discussão que a autora faz tendo como base o conceito de lugar e a interface com os conceitos de espaço e território.
Quando questionados sobre a importância da EF no currículo escolar, houve os professores que apontaram que a importância da disciplina está ainda calcada, prioritariamente, na prática esportiva e nos aspectos relacionados à saúde, orientada puramente pelo aspecto procedimental (fazer), portanto, com frágil expressão crítica e política, diante das atuais orientações curriculares e pressupostos teóricos e metodológicos constituídos no campo científico da área, o que limita a ocupação de um lugar, no sentido que aponta Maria Isabel Cunha ${ }^{9}$. Entretanto, de modo distinto, os professores Renata e Antonio apresentaram outro entendimento sobre a importância da EF no currículo escolar. Para eles, o mais importante é a reflexão sobre a cultura corporal ${ }^{10}$, que se materializa num conjunto de saberes que são socialmente produzidos e historicamente acumulados pela humanidade, com caráter de universalidade. Para a professora Renata, a cultura corporal deve ser refletida, "ela sempre esteve na vida do ser humano, no seu dia a dia, por ela pode-se compreender o mundo e interferir nele" (RENATA).

Observamos que não há uniformidade em torno da importância dada à EF no currículo escolar, há, sim, a predominância de representação voltada para a aprendizagem do esporte e para as questões ligadas à saúde e vinculadas a intervenções centradas em aspectos procedimentais. Segundo Oliveira (1999); Moura et al. (2013), a superação deste tipo de compreensão é um dos desafios para os profissionais da EFE,

9 O que também é sugerido em estudos de (BARBOSA, 2001; MOURA et al., 2013; NASCIMENTO e GARCES, 2013).

10 Cf. Coletivo de autores, 1992. 
em direção a sua legitimidade pedagógica, portanto, um desafio colocado para a ampliação do seu significado político.

A questão do reconhecimento passa pela existência de um padrão comparativo, no entender de Lovosiolo (1996), autor que argumenta que os professores de EFE têm buscado esse padrão comparativo no professorado das outras disciplinas do currículo escolar. Neste sentido, ao indagarmos aos sujeitos desta pesquisa se a disciplina teria o mesmo status de importância que as outras, as respostas foram unânimes - a EF não possui o mesmo status, ela é, sim, desprestigiada. Foi possível perceber, nos argumentos de alguns professores que, historicamente, algumas disciplinas carregam consigo certos "rótulos" que estão cristalizados na comunidade escolar, sendo aceitos especialmente por pais e alunos. Por exemplo, o professor João apontou que há momentos em que esta diferenciação entre as disciplinas fica mais explícita. Ele assim explica: "por exemplo, em um conselho de classe, um aluno ficar em recuperação em matemática, física, nas áreas exatas, parece ser aceitável pela comunidade. Agora, se isso ocorre em disciplinas como Artes, Filosofia, Educação Física; isso é visto como um bicho de sete cabeças".

Segundo Chervel (1988), há certas questões educativas tradicionalmente fixadas no sistema escolar "que estão profundamente inscritas nas mentalidades e constituem, na cultura nacional, um ponto de referência frequentemente julgado imutável" (p.107). Para o autor, existem sinais de distinção entre as disciplinas, no interior da escola, que extrapolam a questão, por exemplo, de programas e horários, perpassando pelas práticas pedagógicas, pelas categorias de docentes, pela grande espe- cialização recebida na universidade e pelas grandes finalidades educativas iniciadoras das disciplinas. Refletindo neste sentido, Souza Júnior e Galvão (2005) apontam que estes sinais entre outros, representam um conflituoso percurso de conquista de legitimidade de uma ou outra disciplina curricular na história das disciplinas escolares.

$\mathrm{Na}$ opinião dos professores de EF entrevistados, o fato de a EF na escola ser desprestigiada está ancorado na representação social que a comunidade escolar faz da disciplina, e que decorre, de certa forma, da experiência escolar que os professores tiveram com a disciplina durante a sua formação na educação básica. O professor Antonio destacou que o fato de as pessoas da comunidade escolar terem vivenciado práticas pedagógicas em que os professores davam a bola para que os alunos jogassem, faz com que as representações voltadas à EFE se consolidem em torno de uma disciplina que é vista, considerada mais como uma atividade do que como um componente curricular. Relatos como o de Antonio expressam o quão nociva pode ser uma prática descomprometida, isolada e distanciada da realidade, bem como as consequentes influências sobre o caráter de sua legitimidade. Com efeito, para Faria et al. (2012), as representações sociais influenciam sobre a legitimação pedagógica e curricular da EFE, incidindo, muitas vezes, na própria atuação dos professores, uma vez que estes podem assumir a "compreensão de si como docentes também de segunda classe" (p.127).

Um último aspecto tratado nesta categoria refere-se ao posicionamento dos professores entrevistados quanto à possível extinção da obrigatoriedade da EF nos currículos escolares. O tema foi abordado 
porque havia interesse de saber quais seriam as implicações da desobrigatoriedade da EF sobre sua legitimidade. Entre os professores entrevistados predominou certo consenso de que ela perderia espaço, por diferentes motivos: as representações dos gestores sobre a disciplina ainda são equivocadas; há certa fragilidade da EF na luta política com relação a outras disciplinas historicamente já privilegiadas; há limitações na compreensão sobre a real contribuição da disciplina no que se refere aos processos de ensino-aprendizagem; além da visível falta de comprometimento de alguns professores.

Em síntese, a questão da legalidade ainda apareceu como fator indispensável e preponderante para a EF. Fora deste âmbito, teria maiores dificuldades para justificar os espaços já conquistados e, sobretudo, para avançar, consolidando-se política e pedagogicamente. Este movimento da EFE pode ser explicitado em Chervel (1988) quando este afirma que o desequilíbrio interno de uma disciplina, ou seja, a falta de tradição pedagógica é um dos fatores que contribuem para a não legitimação de certa disciplina escolar:

O desequilíbrio interno da disciplina, favorecendo determinado componente às custas de um outro, não permite a ela produzir os efeitos buscados de modo que ela se beneficie, por parte dos alunos, de uma motivação suficiente, seja pelo fato das circunstâncias históricas, seja pelo fato das "qualidades pedagógicas" do mestre (CHERVEL, 1988, p.113).

De modo geral, o que podemos afirmar em relação ao status de reconhecimento social da EFE é que ainda prevalece a força de sua legalidade formal em detrimento da consolidação de outros sentidos e significados que, no conceito de Maria Isabel Cunha, poderiam ser identificados como constituição de um lugar para a EFE. Embora se observem movimentos no sentido de ampliar estes significados sociais para a disciplina, ainda há muito para avançar. Portanto, a ideia de EFE como um território, na concepção que propõe Cunha, aparece ainda como um horizonte relativamente distante. A autora diz o seguinte:

A ocupação de um território se dá no confronto entre forças. Ao ocuparmos os lugares, estamos fazendo escolhas que preencherão os espaços e os transformarão em territórios. A escolha de uma dimensão anula a condição da outra se estabelecer. Mesmo assumindo a possibilidade da contradição e da dialética, as forças em tensão revelam predomínios que sinalizam disputas de poder (CUNHA, 2008, p.185).

A EF no IFC campus Sombrio não possui (pelo menos ainda) forças suficientes que the permitam o diálogo com outras áreas, em condições reais de consolidar novos códigos e princípios. Entretanto, a ocupação deste lugar, pela disciplina, na instituição, vem sendo constituída por outras subjetividades, conforme apontam seus professores.

\section{CONSIDERAÇÕES FINAIS}

No presente texto, retomamos os objetivos que orientaram a investigação cujo propósito foi compreender o movimento de constituição da identidade pedagógica e curricular da EF e sua legitimidade no âmbito do Instituto Federal de Educação, Ciência e Tecnologia Catarinense. Nesse 
sentido, buscamos destacar os elementos mais significativos em relação às problemáticas discutidas e tomadas com maior densidade nas categorias de análise.

O estudo dos elementos relacionados à primeira categoria (experiência dos sujeitos com a EFE) apontou que, em geral, a formação dos entrevistados na educação básica esteve calcada em conteúdos vinculados ao modelo esportivo, mais especificamente, em quatro modalidades (futebol, handebol, basquetebol e voleibol). Percebeu-se que o dualismo corpo e mente presente nos modelos higienista/eugenista $\mathrm{e}$ esportivista mostrou-se associado à prática do fazer pelo fazer; que a ação pedagógica, de certa forma, esteve ancorada em pressupostos e orientações do currículo praticado no período da formação; que a disciplina de EF a qual vivenciada foi marcada pela permissividade em relação às escolhas dos estudantes, o que sugere, em certa medida, a desvalorização da disciplina e o consequente descomprometimento dos professores com o próprio processo de ensino-aprendizagem. Além destes aspectos, os entrevistados destacaram que a disciplina, em geral, foi ofertada em turnos contrários e marcada pelo sexismo. Com certeza, tais experiências ainda interferem no imaginário social destes profissionais sobre a EFE e, consequentemente, sobre sua identidade.

No que se refere à formação profissional do professor de EF (segunda categoria), constatamos que diferentes motivos levaram os professores entrevistados a optarem pela formação acadêmica na área e que nem sempre esta foi a sua primeira opção, embora apontem que o envolvimento com o esporte, em suas experiências de vida, influenciou na opção pelo curso. Este aspecto, de certa forma, revela o quanto o fenômeno esportivo pode influenciar escolhas, neste caso, a opção dos profissionais de EF para exercer a docência na escola.

Para os professores, o conhecimento fragmentado da graduação dificultou a compreensão sobre a lógica dos processos escolares. Esse conhecimento, segundo eles, limitou a articulação entre teoria e prática, entre saber científico e saber prático. Tal lacuna, para alguns entrevistados, vai sendo amenizada a partir da inserção na realidade escolar. Sem dúvida, esta dificuldade interfere negativamente nas práticas pedagógicas desenvolvidas no próprio IFC campus Sombrio e também repercute na constituição da identidade e legitimidade da disciplina.

A análise dos elementos relacionados à prática pedagógica e curricular (categoria 3) apontou que no IFC campus Sombrio há ações docentes pautadas por concepções e procedimentos distintos. Não há, em princípio, uma identidade consolidada. O que se observou é um movimento de (re) configuração de identidade no âmbito da disciplina. Não obstante encontrarem-se práticas ancoradas em modelos tradicionais, inclusive desarticuladas e desconectadas com as novas necessidades socioeducativos projetadas pela instituição, há um movimento que busca articulação com o projeto pedagógico do IFC e que se pauta em perspectivas críticas.

Este grupo organiza sua prática, ancorado no desejo e desafio de superar a visão historicamente cristalizada da EFE como uma disciplina que tem pouco a oferecer em relação à formação humana mais ampla. É, portanto, um movimento que objetiva transformar o espaço legitimado formalmente para a EFE em um território constitutivo de nova identidade. Dizendo de outra forma: 
O território tem uma ocupação, e essa revela intencionalidades: a favor de que e contra que se posiciona. Nessa perspectiva, não há territórios neutros. A ocupação de um território se dá no confronto entre forças. Ao ocuparmos os lugares, estamos fazendo escolhas que preencherão os espaços e os transformarão em territórios (CUNHA, 2008, p. 185).

No que se refere ao reconhecimento social (categoria 4), a pesquisa indicou que o espaço da disciplina de EF, no currículo no IFC campus Sombrio, está legitimado muito mais pela questão da legalidade do que por sua importância pedagógica e curricular. Revelou que há, ainda, dificuldades por parte dos sujeitos da comunidade escolar em compreender o caráter da importância social, pedagógica e política da EF. Em geral, a representação social destes sujeitos sobre o reconhecimento social da EFE ainda é limitada, dado que permanece ancorada somente na perspectiva de uma disciplina voltada à aprendizagem do esporte e de questões ligadas à saúde, pautada, portanto, no aspecto procedimental.

Conclui-se que, pela ótica dos profissionais da instituição, a disciplina tem frágil reconhecimento social, e que sua legitimidade pedagógica e curricular, na concepção assumida nesta pesquisa, ainda constitui um desafio a ser superado. Todavia, é possível afirmar que há um caminho já percorrido na direção da constituição de um território para a disciplina, território este que só pode ser alcançado pelo reconhecimento de uma nova identidade, não só no âmbito da área, mas pela sociedade em geral.

Compreende-se que a constituição da identidade pedagógica e curricular da EF e sua legitimidade no âmbito do IFC campus Sombrio vem sendo constituída no processo social, que se constrói com base nos significados sociais e nas suas tradições, que evolui continuamente e que segue influenciado pelos processos relacionais, pelas representações sociais, pela própria ação pedagógica e curricular, e pelo reconhecimento de princípios e códigos em torno da disciplina. Identidade que não se expressa como algo imutável, fixa, concluída, mas sim como construção sócio-histórica, que se modifica com o tempo, o contexto e com relações estabelecidas.

Finalmente, assume-se que a pesquisa possui limitações, que as considerações realizadas a partir da descrição, análise e interpretação das informações possuem caráter específico, portanto, respondem aos objetivos desta investigação, sem o compromisso com generalizações. Supõe-se que o presente estudo seja uma contribuição teórica para o campo da EF em geral e para o adensamento da discussão sobre a identidade pedagógica e curricular da disciplina e sua legitimidade no IFC campus Sombrio.

Reconhecer que as limitações e possibilidades do cotidiano escolar permitem o fortalecimento do debate em torno da complexidade da prática pedagógica e curricular na instituição estudada pode estimular outros movimentos teóricos e práticos necessários para que professores, em especial, os professores de EF, possam acolher as demandas do processo ensino-aprendizagem e compreender a importância pedagógica e curricular da disciplina.

Por fim, tomamos a citação do professor João Paulo Subira Medina sobre a EF:

Não só precisamos alterar o curso ordinário (grifo nosso)- aliás bem "ordinário"- que ela vem seguindo, como 
também buscar a sedimentação de novos padrões culturais e, afinal, lutar por novos padrões de vida. Para uma Educação Física realmente preocupada com o ser humano não basta concordar plenamente com a sociedade. É necessário que faça uma permanente crítica social; seja sensível as diversas formas de repressão a que as pessoas estão sujeitas e as ajudem a entender os seus determinismos e superar os seus condicionamentos, tornado-as cada vez mais livres e humanas (MEDINA, 1994, p.36).

A recomendação de Medina permite acreditar que a escola é lugar privilegiado para a $E F$, e que é neste território que a disciplina precisa configurar definitivamente sua identidade e, portanto, consolidar-se também no âmbito do seu reconhecimento social.

\section{REFERÊNCIAS}

BARBOSA, Claudio L. de Alvarengua. Educação Física Escolar: as representações sociais. Rio de Janeiro: Shape, 2001.

BRACHT, Valter. Educação Física e aprendizagem social. Porto Alegre: Magister, 1997. - Educação Física: a busca da autonomia pedagógica. Rev. da Fundação de Esporte e Turismo, 1(2), 12-19, 1989.

. Mas, afinal, o que estamos perguntando com a pergunta "o que é Educação Física". Rev. Movimento, Ano 02, n.2, p.1-8, junho/1995.

. Identidade e Crise da Educação

Física: um enfoque epistemológico.

In: BRACHT, Valter; CRISORIO,
Ricardo. A Educação física no Brasil e na Argentina: identidade, desafios e perspectivas. Campinas/SP: Autores Associados; Rio de Janeiro: PROSUL, 2003.

BRACHT, Valter; RODRIGUES, Leonardo Lima. As culturas da Educação Física.

Rev. Bras. Cienc. Esporte, Campinas, v. 32, n. 1, p. 93-107, setembro 2010.

BRACHT, Valter; FARIA, Bruno de Almeida; MACHADO, Thiago da Silva. A inovação e o desinvestimento pedagógico na Educação Física escolar: uma leitura a partir da teoria do reconhecimento social. Rev. Motriz, Rio Claro, v.18, n.1, p.120-129, jan./mar. 2012.

CAPARRÓZ, Francisco Eduardo. Parâmetros Curriculares Nacionais de Educação Física: "o que pode ser que não é o que não pode ser que não é". In: BRACHT, Valter; CRISORIO, Ricardo. A Educação física no Brasil e na Argentina: identidade, desafios e perspectivas. Campinas/SP: Autores Associados; Rio de Janeiro: PROSUL, 2003.

CASTELLANI FILHO, Lino. Educação Física no Brasil: A história que não se conta. 12. ed. Campinas/SP: Papirus. 2006.

CHERVEL, André. História das disciplinas escolares: reflexões sobre um campo de pesquisa. Rev. Histoire de I 'éducation, $\mathrm{n}^{\circ}$. 38, p. 61-119, maio de 1988. Tradução de Guacira Lopes Louro.

COLETIVO DE AUTORES. Metodologia do ensino de educação física / coletivo de autores. São Paulo: Cortez, 1992.

CUNHA, Maria Isabel da. Os conceitos de espaço, lugar e território nos processos analíticos da formação dos docentes universitários. Rev. Educação Unisinos, São Leopoldo, v.12, no 3, 182-186, setembro/dezembro 2008. 
DA COSTA, Lamartine P. Formação Profissional em Educação Física, esporte e lazer no Brasil: memória, diagnóstico e perspectivas. Blumenau: Ed. FURB, 1999. 243p.

DARIDO, Suraya Cristina. Educação Física na escola: questões e reflexões. Araras/ SP: Gráfica e Editora Topázio, 1999.

DIECKERT, Jürgen. Uma retrospectiva de (meus) 30 anos de atividade de Assessor, de magistério e de pesquisa na formação de professores de Educação física no Brasil. In: STRAMANN, Reiner Hildebrant; TAFFAREL, Celi Zulke. Currículo e educação física: formação de professores e prática pedagógica nas escolas. ljuí: Ed. Unijuí, 2007. 472p.

FARIA, Bruno de Almeida; MACHADO, Thiago da Silva; BRACHT, Valter. A inovação e o desinvestimento pedagógico na Educação Física escolar: uma leitura a partir da teoria do reconhecimento social. Rev. Motriz, Rio Claro, v.18 n.1, p.120-129, jan./ mar. 2012.

FERRAZ, Osvaldo Luiz; CORREIA, Walter Roberto. Teorias curriculares, perspectivas teóricas em Educação Física Escolar e implicações para a formação docente. Rev. Bras. Educ. Fís. Esporte, São Paulo, v.26, n.3, p.531540, jul./set. 2012.

FIGUEIREDO, Zenólia Christina Campos. Formação Docente, Currículo e Saber. In: CAPARRÓZ, Francisco Eduardo. Educação física escolar: política, investigação e intervenção. Vol.1. Vitória/ES: PROTEORIA, 2001.

FLICK, Uwe. Introdução à pesquisa qualitativa. Tradução Joice Elias Costa. 3. ed. Porto Alegre: Artmed, 2009. $405 \mathrm{p}$.
FONTE, Sandra Soares Della. O passado em agonia: da criação de reducionismos ou sobre como matar a historicidade. In: CAPARRÓZ, Francisco Eduardo. Educação física escolar: política, investigação e intervenção. Vol.1. Vitória/ES: PROTEORIA, 2001.

JANUÁRIO, Carlos. O Desenvolvimento Profissional: a aprendizagem de ser professor e o processo de rotinização das decisões préinterativas em professores de Educação Física. In: NASCIMENTO, Juarez Vieira do; FARIAS, Gelcemar Oliveira, organizadores. Construção da Identidade Profissional em Educação Física: da formação à intervenção. Florianópolis: Ed. Da UDESC, 2012.

KRÜGER, Leonardo Germano. As concepções de formação profissional da licenciatura em Educação Física: trajetórias docentes e suas perspectivas contributivas. Santa Maria: Universidade Federal de Santa Maria, 2007. Dissertação (Mestrado) Universidade Federal de Santa Maria, Centro de Educação, Programa de Pós-graduação em Educação, 2007.

KUNZ, Elenor. Educação Física: ensino e mudanças. 2. ed. Ijuí: UNIJUÍ, 2001a. p.208(Coleção Educação Física)

- Transformação didáticopedagógica do esporte. 4. ed. ljuí: UNIJUí, 2001b. p.160(Coleção Educação Física)

LUDKE, Menga; ANDRE, Marli E. D. A. Pesquisa em educação: abordagens qualitativas. São Paulo: EPU, 1986. 99p. LOVISOLO, Hugo. Mas, afinal, o que é Edu-cação Física?: a favor da mediação e contra os radicalismos. Rev. Movimento, Ano 2, N. 2. Junho/95. Edição Especial. 
. Hegemonia e legitimidade nas ciências dos esportes. Rev. Motus Corporis, Rio de Janeiro, v.3, n.02, p.51-72, dez. 1996.

MARQUES, Mário Osório. A formação do profissional da educação. ljuí: Ed. UNIJUÍ, 2000.

MEDINA, João Paulo Subirá. A Educação

Física cuida do corpo...e "mente": bases para a renovação e transformação da Educação Física. 12. ed. Campinas/SP: Papirus, 1994.

MINAYO, Maria Cecilia de Souza; DESLANDES, Suely Ferreira; GOMES, Romeu. Pesquisa social: teoria, método e criatividade. 30. ed. Petrópolis: Vozes, 2011. 108p

MOLINA, Rosane Maria Kreusburg. O enfoque teórico metodológico qualitativo e o estudo de caso: uma reflexão introdutória. In: MOLINA NETO, Vicente; TRIVIÑOS, Augusto Nibaldo Silva. A Pesquisa qualitativa na educação física: alternativas metodológicas. 3. ed. Porto Alegre (RS): Ed. da UFRGS: Sulina, 2010. 176 p.

MOLINA NETO, Vicente. A prática dos professores de educação física das escolas públicas de Porto Alegre. Rev. Movimento, Porto Alegre, Ano V, N.09, p.31-46, 1998/2.

MOREIRA, Wagner Wey. Por uma concepção sistêmica na pedagogia do movimento. In: GEBARA, Ademir et al. Educação Física e esportes: perspectivas para o século XXI. 3. ed. Campinas/SP: Papirus, 1999.

MOURA, Diego Luz; ANTUNES, Marcelo Moreira; COSTA, Kamilla Ribeiro Nunes; et al. A percepção de diretores sobre a Educação Física escolar. EFDeportes. com, Revista Digital. Buenos Aires, Año 17, No 178, Marzo de 2013.

NASCIMENTO, Bianca Bueno do; GARCES, Solange Beatriz Billig. Educação Física ou rola bola? A percepção da comunidade escolar sobre as aulas de Educação Física. Revista Digital EFDeportes.com, Buenos Aires, Ano 17, No 178, Março de 2013.

NEIRA, Marcos Garcia. Ensino de Educação

Física. São Paulo: Thomson Learning, 2007.

NOVOA, Antonio. Formação de professores e profissão docente. In: NOVOA, Antonio. Os professores e a sua formação. 2. ed. Lisboa: Dom Quixote, 1995. 158p. (Nova enciclopédia; 39. Coleção temas de educação, 1)

NUNES, Mario Luiz F.; RÚBIO, Kátia. O (s) Currículo (s) da Educação Física e a constituição da identidade de seus sujeitos. Rev. Currículo sem Fronteiras, v.8, n.2, p. 55-77, Jul/Dez, 2008.

OLIVEIRA, Marcus Aurelio Taborda de. Existe espaço para o Ensino de Educação Física na Escola Básica? Rev. Pensar a Prática 2, p.119-135, Jun./Jun. 1998/1999.

PAIXÃO SANTOS, L.L.C. Formação de professores e saberes docentes. In: SHIGUNOV NETO, A; BOMURA MACIEL, L.S. (org). Reflexões sobre a Formação de Professores. Campinas: Papirus, p.89-102. 2002.

PALMA, Ângela Pereira Teixeira Victoria; OLIVEIRA, Amauri Aparecido Bassoli; PALMA, José Augusto Victoria. Educação Física e a organização curricular: educação infantil, ensino fundamental, ensino médio. 2. ed. Londrina: EDUEL, 2010. 
ROSARIO, Luís Fernando Rocho; DARIDO, Suraya Cristina. A sistematização dos conteúdos da educação física na escola: a perspectiva dos professores experientes. Rev. Motriz, Rio Claro, v.11, n.3, p.167-178, set./dez. 2005.

SACRISTÁN, Jose Gimeno. O Currículo: uma reflexão sobre a prática. 3. ed. Porto Alegre: Artmed, 2000.

SADI, Renato Sampaio. A qualidade da Educação Física Escolar. In: CAPARRÓZ, Francisco Eduardo. Educação física escolar: política, investigação e intervenção. Vol.1. Vitória/ES: PROTEORIA, 2001.

SANCHO, Juana Maria Gil. Inovação e investigação educativa: aproximação de uma relação incerta. In: MOLINA NETO, Vicente; TRIVIÑOS, Augusto Nibaldo Silva. A Pesquisa qualitativa na educação física: alternativas metodológicas. 3. ed. Porto Alegre (RS): Ed. da UFRGS: Sulina, 2010. 176 p.

SELBACH, Simone. Educação Física e didática. Petrópolis/RJ: Vozes, 2010.

SOUZA JÚNIOR, Marcílio. O saber e do fazer pedagógicos: a educação física como componente curricular_? Isso é história. Recife: EDUPE, 1999. . O saber e o fazer pedagógicos da Educação Física na cultura escolar: o que é um componente curricular? In: CAPARRÓZ, Francisco
Eduardo. Educação física escolar: política, investigação e intervenção. Vol.1. Vitória/ES: PROTEORIA, 2001. SOUZA JÚNIOR, Marcílio; GALVÃO, Ana Maria de Oliveira. História das disciplinas escolares e história da educação: algumas reflexões. Rev. Educação e Pesquisa, São Paulo, v. 31, n. 3, p. 391-408, set./dez. 2005.

SOUZA NETO, Samuel et al. A formação do profissional de Educação Física no Brasil: uma história sob a perspectiva da legislação federal no século XX. Rev. Bras. Cienc. Esporte, Campinas, v.25, n.2, p.113-128, jan. 2004.

TARDIF, Maurice. Saberes profissionais dos professores e conhecimentos universitários: Elementos para uma epistemologia da prática profissional dos professores e suas consequências em relação à formação para o magistério. Rev. Brasileira de Educação, n.13, jan/fev/mar/abr. 2000. Disponível em: < http://www.anped.org.br/rbe/ rbedigital/RBDE13/RBDE13_05 > . Acesso em: 15 mai de 2013.

VAZ, Alexandre Fernandez; SAYÃO, Deborah Thome; PINTO, Fabio Machado. Educação do corpo e formação de professores: reflexões de professores sobre a prática de ensino de educação física. Florianópolis, SC: Ed. da UFSC, 2002. 110p. 


\title{
IDENTITY EDUCATIONAL AND CURRICULUM OF PHYSICAL EDUCATION SCHOOL: RECOGNITION AND LEGITIMACY TERRITORIES AT THE FEDERAL INSTITUTE OF SANTA CATARINA
}

\begin{abstract}
This work it is a study under the Federal Institute of Santa Catarina (IFC) on the movement of formation of pedagogical and curricular identity of Physical Education (EF) and its legitimacy. The research problem was summarized in the following question: how the pedagogical and curricular identity EF under the IFC has been made? It is characterized as a qualitative work, exploratory base and case study. The main procedures for obtaining the information were: documental analysis, participant observation and semi-structured interviews. Among the findings of the research, in summary, it was concluded that: i) the experiences of the subject with the discipline of Physical Education, while elementary school students, as well as the professional constitution EF teacher were characterized predominantly situations teaching and learning geared to sports content; ii) the pedagogical practice of EF teachers is basically based on two curricular perspectives: traditional and critical; iii) the social recognition of EF as a curriculum subject is not consolidated by the school community.
\end{abstract}

Keywords: School Physical Education; Teaching Practice; Curriculum; Identity

\section{IDENTIDAD PEDAGÓGICA Y CURRICULAR DE LA EDUCACIÓN FÍSICA ESCOLAR: TERRITORIOS RECONOCIMIENTO Y LEGITIMIDAD EN EL INSTITUTO FEDERAL DE SANTA CATARINA}

\section{RESUMEN}

Este trabajo es un estudio en el marco del Instituto Federal de Santa Catarina (IFC) sobre el movimiento de formación de la identidad pedagógica y curricular de Educación Física (EF) y su legitimidad. El problema de investigación se resume en la siguiente pregunta: cómo se ha hecho la EF identidad pedagógica y curricular bajo la IFC? Se caracteriza por ser un trabajo cualitativo, exploratorio y de base estudio de caso. Los principales procedimientos para la obtención de la información fueron: análisis documental, la observación participante y entrevistas semiestructuradas. Entre las conclusiones de la investigación, en resumen, se concluyó que: situaciones i) las experiencias del sujeto con la disciplina de educación física, mientras que los estudiantes de la escuela primaria, así como el maestro constitución EF profesional se caracterizan predominantemente enseñanza y el aprendizaje orientado a contenidos deportivos; ii) la práctica pedagógica de los profesores de educación física se basa básicamente en dos perspectivas curriculares: tradicional y crítica; iii) el reconocimiento social de la EF como materia curricular no está consolidada por la comunidad escolar.

Palabras clave: Escuela de Educación Física; Enseñanza Práctica; Currículo; Identidad 